\title{
Relationship between human tumour angiogenic profile and combretastatin-induced vascular shutdown: an exploratory study
}

\author{
A Gaya*, , F Daley ${ }^{2}$, NJ Taylor ${ }^{3}$, G Tozer ${ }^{2}$, U Qureshi ${ }^{4}$, A Padhani ${ }^{3}$, RB Pedley ${ }^{4}$, R Begent ${ }^{4}$, D Wellsted ${ }^{5}$, \\ JJ Stirling ${ }^{3}$ and G Rustin ${ }^{6}$
}

'Department of Clinical Oncology, Guy's \& St Thomas' Hospitals, London SEI 7EH, UK; ' Gray Cancer Institute, Northwood, Middlesex HA6 2RN, UK; ${ }^{3}$ Paul Strickland Scanner Centre, Northwood, Middlesex HA6 2RN, UK; ${ }^{4}$ Department of Medical Oncology, Royal Free Hospital, London NW3 2QG, UK; ${ }^{5}$ Department of Statistics, University of Hertfordshire, College Lane, Hatfield, AL 10 9AB, UK; ${ }^{6}$ Department of Medical Oncology, Mount Vernon Hospital, Northwood, Middlesex HA6 2RN, UK

\begin{abstract}
Combretastatin-A4-phosphate (CA4P) acts most effectively against immature tumour vasculature. We investigated whether histological angiogenic profile can explain the differential sensitivity of human tumours to CA4P, by correlating the kinetic changes demonstrated by dynamic MRI (DCE-MRI) in response to CA4P, with tumour immunohistochemical angiogenic markers. Tissue was received from 24 patients (mean age 59, range 32-73, 18 women, 6 men). An angiogenic profile was performed using standard immunohistochemical techniques. Dynamic MRI data were obtained for the same patients before and $4 \mathrm{~h}$ after CA4P. Three patients showed a statistically significant fall in $K^{\text {trans }}$ following CA4P, and one a statistically significant fall in IAUGC 60 . No statistically significant correlations were seen between the continuous or categorical variables and the DCE-MRI kinetic parameters other than between ang-2 and $K^{\text {trans }}(P=0.044)$. In conclusion, we found no strong relationships between changes in DCE-MRI kinetic variables following CA4P and the immunohistochemical angiogenic profile.
\end{abstract}

British Journal of Cancer (2008) 99, 32 I-326. doi:I0.1038/sj.bjc.6604426 www.bjcancer.com

Published online 8 July 2008

(c) 2008 Cancer Research UK

Keywords: combretastatin; immunohistochemistry; vascular maturity; dynamic MRl; microvessel density; angiogenesis

Combretastatin-A4-phosphate (CA4P) is a tubulin-binding, selective vascular disruptive agent (VDA) that causes rapid shutdown of blood flow to tumours with minimal effects on normal vasculature. Tumour endothelial cells are often immunohistochemically immature, lacking smooth muscle and pericyte coverage, and more sensitive to the effects of VDAs probably because the intracellular cytoskeleton is less developed (Tozer et al, 2005). Our aim was to determine human tumour vascular maturity using an immunohistochemical angiogenic profile, and to study any relationship with CA4P response assessed by change in DCE-MRI kinetic variables.

We selected antibodies to differentiate immature vascular endothelium - CD105 (endoglin), CD61 ( $\beta_{3}$-integrin), a pericyte marker $\alpha$-smooth muscle actin ( $\alpha$ SMA), a marker of hypoxia (Glut-1), proliferation marker (Ki-67), and markers associated with the angiogenic switch (VEGF, PDGFB, angiopoietin-1, and angiopoietin-2).

\section{MATERIALS AND METHODS}

Following ethics approval, patients enrolled in Mount Vernon phase I CA4P studies (CR-UK PH1/066 \& PH1/092) who underwent DCE-MRI analysis were identified. Records were obtained from 26 identified patients and tissue was available for 24 patients

*Correspondence: Dr A Gaya; E-mail: andrew.gaya@gstt.nhs.uk Revised 28 April 2008; accepted 28 April 2008; published online 8 July 2008
(Table 1). A full set of DCE-MRI data was available for 21. Tissue blocks were coded to conceal patient identity. Sections $(4 \mu \mathrm{m})$ were cut onto slides, and stained with the panel of antibodies at concentrations and with control samples illustrated in Table 2.

\section{Immunohistochemical procedures}

All sections were deparaffinised in xylene and rehydrated through graded alcohols to water.

CD34 and $\alpha S M A$ double staining Dako's Cytomation Envision double stain system (K5361) (Dako Ltd., Cambridgeshire, UK), was used performed according to the manufacturer's instructions. Specimens were counterstained using Gills haematoxylin (01500E; Surgipath Europe Ltd.) for $7 \mathrm{~s}$ and washed. The samples were mounted and cover slipped using Dako Faramount aqueous mounting medium (S3025).

CD105 We used Dako's Catalysed Signal Amplification staining system (K1497) and followed the manufacturer's instructions exactly.

VEGF, Ki-67, and Glut-1 Dako's Universal autostainer (Dako) was used. Antigen retrieval was performed in $0.01 \mathrm{M}$ citric acid $\mathrm{pH}$ 6. Glut- 1 and Ki-67 were microwaved for $3 \times 4$ min and VEGF for $4 \times 4 \mathrm{~min}$. Optimum antigen retrieval times were determined from titration experiments. 
Table I Patient demographics and histologies

\begin{tabular}{|c|c|c|c|c|c|c|}
\hline Patient ID & Patient age & Phase I trial & Tumour site & Histology & $\begin{array}{l}\text { Date specimen } \\
\text { taken }\end{array}$ & $\begin{array}{l}\text { CA4P Dose } \\
\left(\mathrm{mg} \mathrm{m}^{-2}\right)\end{array}$ \\
\hline 01 & 64 & $\begin{array}{l}\mathrm{PHI} / 066 \text { UK } \\
\text { phase I single agent } \\
\text { CA4P }\end{array}$ & Paratesticular & Spindle cell sarcoma & 08/1999 & 52 \\
\hline 02 & 51 & & Adrenal & Carcinoma & $06 / 1993$ & 68 \\
\hline 03 & 65 & & Uterus & Leiomyosarcoma & 03/1999 & 88 \\
\hline 04 & 63 & & Renal & Renal papillary carcinoma & | |/1997 & 40 \\
\hline 07 & 71 & & Rectum & & $01 / 1997$ & 52 \\
\hline 08 & 68 & & Ovary & Papillary adenocarcinoma & 05/1994 & 5 \\
\hline 09 & 62 & & Uterus & Leiomyosarcoma & $05 / 1998$ & 88 \\
\hline 10 & 60 & & Peritoneum & Primary peritoneal carcinoma & 09/1999 & 52 \\
\hline 11 & 50 & & Right tibia & Leiomyosarcoma & 10/1997 & 68 \\
\hline 12 & 60 & & Ovary & Papillary serous adenocarcinoma & 03/1994 & 114 \\
\hline 13 & 49 & & Lung & Adenocarcinoma & $04 / 1998$ & 40 \\
\hline 19 & 60 & & & & $02 / 1999$ & 45 \\
\hline 20 & 73 & & & & $|1 / 200|$ & 45 \\
\hline 21 & 57 & $\mathrm{PHI} / 066$ & Uterus & Leiomyosarcoma & $07 / 1998$ & $\mathrm{~N} / \mathrm{A}$ \\
\hline 22 & 70 & $\mathrm{PHI} / 092$ (A5B7) & Colon & G2 Adenocarcinoma & $10 / 2003$ & 45 \\
\hline 23 & 66 & & & Adenocarcinoma & 08/200I & 45 \\
\hline 24 & 32 & & & & | |/2002 & 45 \\
\hline
\end{tabular}

Table 2 Angiogenic expression antibody profile

\begin{tabular}{|c|c|c|c|c|c|}
\hline Antibody & Type of marker & Source & Concentration & $\begin{array}{l}\text { Specificity and non- } \\
\text { specific staining }\end{array}$ & Control sample \\
\hline CD34 & Vascular & Novocastra NCL-END & $1: 60$ & $\begin{array}{l}\text { Endothelium, connective } \\
\text { tissue, erythrocytes }\end{array}$ & Tonsil \\
\hline$\alpha S M A$ & & Sigma A2547 & $1: 20000$ & Smooth muscle & Tonsil \\
\hline CDI05 & & Dako M3527 & $1: 1000$ & $\begin{array}{l}\text { Proliferating endothelium, } \\
\text { activated macrophages }\end{array}$ & $\begin{array}{l}\text { Human breast } \\
\text { carcinoma }\end{array}$ \\
\hline CD6I & & $\begin{array}{l}\text { Novocastra NCL-CD6I- } \\
308\end{array}$ & $1: 100$ & $\begin{array}{l}\text { Endothelium, platelets, } \\
\text { megakaryocytes, } \\
\text { monocytes, macrophages }\end{array}$ & Tonsil, human placenta \\
\hline VEGF & & Neomarkers MS-1467 & $1: 100$ & $121,165,189$ Isoforms & $\begin{array}{l}\text { Human breast } \\
\text { carcinoma }\end{array}$ \\
\hline $\mathrm{Ki}-67$ & Proliferation & Dako M7240 & $1: 200$ & $\begin{array}{l}345,395 \text { Isoforms. nuclear } \\
\text { expression }\end{array}$ & Tonsil \\
\hline Glut-I & Hypoxia & Dako A3536 & $1: 200$ & Erythrocytes, tumour & Tonsil \\
\hline PDGF & $\begin{array}{l}\text { Vascular/tumour/ } \\
\text { stromal }\end{array}$ & $\begin{array}{l}\text { Novocastra NCL-PDEGF } \\
\text { P-GF.44c }\end{array}$ & $1: 60$ & $\begin{array}{l}\text { Tumour, macrophages, } \\
\text { stroma, glia, epithelia }\end{array}$ & Tonsil, human placenta \\
\hline
\end{tabular}

SMA $\alpha=\alpha$-smooth muscle actin.

\section{Ang-1, Ang-2, PDGF, and CD61}

Benchside manual staining procedures were used. Endogenous peroxidase activity was quenched with $1.5 \%$ hydrogen peroxide in methanol for $10 \mathrm{~min}$. Antigen retrieval was performed by microwaving in $0.01 \mathrm{M}$ citric acid $\mathrm{pH} 6$ for $10 \mathrm{~min}$ (ang-1) and $20 \mathrm{~min}$ (ang-2). After washing in Tris-buffered saline tween-20 (TBST) primary antibody was applied as shown in Table 2, and incubated overnight at $4^{\circ} \mathrm{C}$. After rinsing in TBST, Dako Envision anti-rabbit secondary antibody (K5007) with peroxidase was applied for $30 \mathrm{~min}$. Antigen was developed with diaminobenzidine, slides counterstained with haematoxylin, dehydrated, cleared, and mounted. For CD61 and PDGF Vectastain's mouse IgG normal horse serum (Vector Labs, Burlingame, CA, USA) diluted in TBS was applied for $30 \mathrm{~min}$. A horse anti-mouse biotinylated secondary was then applied, followed by incubation with streptavidinperoxidase reagent.

\section{Immunohistochemical profile analysis}

Each slide was assessed using a Zeiss Axioskop microscope, with Visilog 5.0 (Noesis) image capture software. The random field 
Table 3 Results-angiogenic expression profile of 24 human tumours

\begin{tabular}{|c|c|c|c|c|c|c|c|c|c|c|}
\hline Patient ID & $\begin{array}{l}\text { CD34 MVD } \\
\text { per } \mathrm{mm}^{2}\end{array}$ & $\begin{array}{c}\text { SMA PCI } \\
(\%)\end{array}$ & $\begin{array}{l}\text { CDI05 MVD } \\
\text { per } \mathrm{mm}^{2}\end{array}$ & VEGF & $\begin{array}{c}\text { Ki-67 } \\
(\%)\end{array}$ & $\begin{array}{l}\text { Glut-I } \\
(\%)\end{array}$ & Ang-I & Ang-2 & PDGF & $\begin{array}{l}\text { CD6I MVD } \\
\text { per } \mathrm{mm}^{2}\end{array}$ \\
\hline 01 & 153.67 & 31.70 & 6.88 & 0 & ND & 0.5 & ND & ND & ND & ND \\
\hline 04 & 97.48 & 85.73 & 53.90 & 2 & 15.0 & 15.0 & 2 & 3 & 2 & 19.50 \\
\hline 05 & 127.29 & 73.69 & 57.34 & 2 & 30.0 & 10.0 & I & 2 & 0 & 26.38 \\
\hline 06 & 26.38 & 47.50 & 13.76 & 0 & 1.0 & 1.0 & 3 & 3 & 0 & 11.47 \\
\hline 09 & 137.61 & 59.03 & 10.32 & 0 & 10.0 & 1.0 & 2 & 1 & 0 & 17.20 \\
\hline 10 & 96.33 & 41.54 & 38.99 & 2 & 50.0 & 30.0 & 0 & 2 & । & 43.58 \\
\hline II & 151.38 & 72.51 & 59.63 & 0 & 2.0 & 0.5 & I & 2 & 0 & 10.32 \\
\hline 12 & 60.78 & 55.58 & 19.50 & 2 & 40.0 & 30.0 & 0 & I & 0 & 6.88 \\
\hline 13 & 83.72 & 57.14 & 10.32 & 2 & 5.0 & 0.5 & । & 1 & 0 & 1.15 \\
\hline 14 & 160.55 & 20.53 & 76.83 & 2 & 10.0 & 5.0 & I & 2 & 0 & 29.82 \\
\hline 15 & 150.23 & 30.60 & 30.96 & 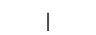 & 15.0 & 25.0 & i & 3 & 0 & 19.50 \\
\hline 21 & 79.13 & 32.63 & 36.70 & 3 & 1.0 & 60.0 & I & 3 & I & 27.52 \\
\hline 22 & 82.57 & 79.83 & 11.47 & 2 & 40.0 & 25.0 & 2 & 2 & 0 & 9.17 \\
\hline 23 & 142.09 & 60.85 & 3.40 & 3 & 40.0 & 2.0 & I & I & 0 & 8.52 \\
\hline 24 & 178.90 & 53.00 & 73.39 & 2 & 25.0 & 15.0 & 3 & 3 & 1 & $|2.6|$ \\
\hline
\end{tabular}

$\mathrm{MVD}=$ microvessel density; $\mathrm{ND}=$ not done, due to lack of available tumour tissue; $\mathrm{PCl}=$ pericyte coverage index. For the categorical variables, $0=$ negative; $\mathrm{I}=$ weak expression; 2 = moderate expression; 3 = strong expression.

techniques described by Eberhard et al (2000) were used. Any $\mathrm{CD}_{3}{ }^{+}$endothelial cells that were distinctly separate from other microvessels at high power were considered individual vessels, and recorded as the number of vessels per high power field. $\alpha \mathrm{SMA}$ staining was analysed concurrently - any $\mathrm{CD}^{+} 4^{+}$vessel also $\alpha \mathrm{SMA}^{+}$was recorded. Mean microvessel density (MVD per $\mathrm{mm}^{2}$ ) and pericyte coverage index (PCI) were calculated after analysing at least 20 random fields per slide (Table 3 ). To determine the Ki-67 proliferation index (\%) or Glut-1 hypoxia index (\%) each slide was scanned at low and high magnification. A semiquantitative visual assessment was made across the slide of the proportion of tumour cells staining positively (Table 3 ).

The following antigens were analysed using a categorical scale, with the proportion of immunoreactive cells graded as weak, moderate, or strong by direct visual assessment at low $(\times 50)$ and high $(\times 400)$ magnification (Table 3$)$. The most appropriate cutoff values were selected from previous studies; VEGF: absent $(<5 \%)$, weak $(5-25 \%)$, moderate $(25-50 \%)$, and strong $(>50 \%)$ (Erdem et al. 2007); Ang-1/2: cytoplasmic expression predominantly and grading system as for VEGF (Lind et al, 2005); PDGF: highly expressed in stroma; absent ( $<1 \%$ tumour staining), weak $(1-10 \%)$, moderate $(10-25 \%)$, and strong ( $>25 \%)$ (Barnhill et al, 1996).

Random results were checked by an experienced immunohistochemist (FD), who had not seen the initial data. In case of disagreement as to the correct result, that slide was analysed by a consultant histopathologist.

\section{DCE-MRI data}

DCE-MRI involves the rapid acquisition of sets of T1-weighted images through tumour as an intravenous bolus of contrast agent is injected. The change in signal intensity over time can be analysed with mathematical models (Tofts, 1997). Quantitative kinetic variables are derived that provide information about tumour microcirculation as they are indirectly related to perfusion, vascular permeability, and vessel surface area (d'Arcy et al, 2006).
The IAUGC (initial area under the gadolinium concentrationtime curve - units: $\mathrm{mm} \mathrm{min)} \mathrm{is} \mathrm{calculated} \mathrm{for} \mathrm{the} \mathrm{first} 60 \mathrm{~s}$ following Gd-DTPA injection (Evelhoch, 1999; Evelhoch et al, 2004). It has the advantage of being a quantitative variable that is obtained without mathematical modelling or knowledge of the arterial input function. It is a measure of how much contrast agent is taken up by the tumour in the first $60 \mathrm{~s}$ post-Gd-DTPA injection and is influenced by tumour blood flow rate and tumour vessel permeability. By using AUC from the Gd-DTPA concentration time curve rather than from the signal intensity time curve, the problem of dependence of signal enhancement on tissue T1 levels is avoided.

The transfer constants for Gd-DTPA diffusion into the tumour extravascular extracellular space (EES) from blood plasma $\left(K^{\text {trans }}\right)$ and back again $\left(k_{\mathrm{ep}}\right)$ can be calculated using Tofts' mathematical model (Tofts and Kermode, 1991; Tofts et al, 1999). $K^{\text {trans }}$ (and $k_{\text {ep }}$ ) have both blood flow rate and permeability components as Gd-DTPA is not freely diffusible and their biological meaning is dependent on the balance between capillary permeability and blood flow in the tissue of interest. In high permeability tissues, $K^{\text {trans }}$ is equal to the blood plasma flow per unit volume of tissue. In low permeability tissues such as the brain, it is equal to the permeability surface area product between the blood plasma and the EES per unit volume of tissue (Tofts, 1997). In most tumours the situation is likely to be somewhere between these two extremes.

Studies were performed on a $1.5 \mathrm{~T}$ scanner as previously described (Galbraith et al, 2003). Images were analysed using specialist software (Magnetic Resonance Imaging Workbench (MRIW), Institute of Cancer Research, London) (d'Arcy et al, 2006). A dynamic analysis was performed using MRIW for each pixel within the region of interest on each slice. The MRIW converts signal intensities of the T1-weighted DCE-MRI data set into $\mathrm{T} 1$ relaxation rates and then into Gd-DTPA concentrations for individual voxels, using the methods described by Parker et al (1997). Standardised terms were employed as defined in Tofts et al (1999). The percentage change from mean baseline kinetic variables following CA4P was calculated (Table 4). 
Table 4 Percentage change in DCE-MRI kinetic parameters $4 \mathrm{~h}$ following infusion of CA4P

\begin{tabular}{|c|c|c|c|}
\hline $\begin{array}{l}\text { Patient } \\
\text { ID }\end{array}$ & $\begin{array}{l}\text { CA4P Dose } \\
\left(\mathrm{mg} \mathrm{m}^{-2}\right)\end{array}$ & $\begin{array}{l}\% \text { Change } K^{\text {trans }} \\
\text { post-CA4P }\end{array}$ & $\begin{array}{c}\% \text { Change IAUGC } 60 \\
\text { post-CA4P }\end{array}$ \\
\hline 04 & 40 & 63.27 & 15.66 \\
\hline 13 & & 15.02 & 186.00 \\
\hline 18 & 45 & -22.91 & -8.38 \\
\hline 19 & & 26.53 & 17.99 \\
\hline 20 & & 39.71 & 31.94 \\
\hline 23 & & -30.32 & -30.03 \\
\hline 24 & & 36.51 & 29.43 \\
\hline 01 & 52 & -29.56 & -12.26 \\
\hline 06 & & 65.75 & | 46.30 \\
\hline 07 & & 7.38 & -23.81 \\
\hline 10 & & -67.14 & -58.92 \\
\hline 02 & 68 & -30.61 & -19.23 \\
\hline 05 & & 1.59 & -7.32 \\
\hline II & & -0.35 & -17.02 \\
\hline 17 & & | | |.84 & -15.44 \\
\hline 03 & 88 & -75.20 & -57.65 \\
\hline 09 & & -58.02 & -58.26 \\
\hline 16 & & 33.01 & -1.88 \\
\hline 12 & 114 & -65.49 & -90.21 \\
\hline 14 & & -20.00 & -13.87 \\
\hline 15 & & 93.46 & 82.38 \\
\hline
\end{tabular}

Statistically significant positive or negative values in bold. There is no obvious visual relationship between CA4P dose and fall in kinetic parameters, or correlation with vascular markers. There are three missing patients: 08 CA4P dose too low $\left(5 \mathrm{mg} \mathrm{m}^{-2}\right), 21 \mathrm{WF}$ no data available, $22 \mathrm{EH}$ severe motion artefact - data unusable.

\section{Statistical analysis}

Measurement error (Bland and Altman, 1996) was used to define confidence intervals for the DCE-MRI variables. Linear regression and correlation analysis were used to test for relationships between the continuous variables and MRI data. Analysis of Variance was used to test for relationships between categorical variables and MRI data.

\section{RESULTS}

Tissue was received from 24 patients (mean age 59, range $32-73$, 18 women, 6 men). Eighteen patients were taken from the PH1/066 single agent UK CA4P trial (Rustin et al, 2003), and 6 from the PH1/092 CA4P + anti-CEA antibody study (Gaya AM et al, 2008, unpublished). The most common histological subtypes (Table 1) were colorectal adenocarcinoma (7), uterine leiomyosarcoma (4), and ovarian adenocarcinoma (3). The age of the tumour blocks varied between 6 months and 21 years. All but one block contained primary tumour from surgical specimens, not metastatic tissue as patients were not rebiopsied before entrance to the phase I trials. We only studied patients who received doses of CA4P between 40 and $114 \mathrm{mg} \mathrm{m}^{-2}$ that have been associated with changes in DCE-MRI kinetic variables.

There was a wide range of DCE-MRI variable change following CA4P (Table 4). Percentage change in $K^{\text {trans }}$ from mean baseline following CA4P varied between +111 and $-75 \%$, and IAUGC $_{60}$ between +186 and $-90 \%$. In reality, only falls in these parameters (consistent with tumour vascular shutdown) are clinically significant. The $95 \%$ confidence interval for $K^{\text {trans }}$ change (determined from repeatability analysis in the individual studies and repeated with the combined data) was -62.5 to $+166.5 \%$, IAUGC $_{60} \pm 80 \%$. There was no obvious visual relationship seen between CA4P dose and fall in kinetic parameters (Table 4). Three patients $(3,10,12)$ showed significant falls in $K^{\text {trans }}$ following CA4P (outside $95 \% \mathrm{CI}$ ), and only 1 patient (12) a significant fall in IAUGC $_{60}$.
No statistically significant correlations were seen between the continuous or categorical variables and the DCE-MRI kinetic variables (Tables $5 \mathrm{a}$ and $\mathrm{b}$ ) other than between ang- 2 and $K^{\text {trans }}$ $(P=0.044)$. Inspecting Tables 3 and 4 , there are no obvious relationships between the angiogenic profile and DCE-MRI data.

\section{DISCUSSION}

We found no obvious relationships between changes in DCE-MRI variables and the immunohistochemical angiogenic profile. This suggests immunohistochemical analysis of patients' tumours is unlikely to be useful in predicting response to VDA therapy. There was enormous variability seen both in the DCE-MRI kinetic variables and the immunohistochemistry. It is difficult to know whether the variability is related to the MRI and immunohistochemical techniques or is due to specific tumour characteristics that are of interest to us ie vascular maturity.

The variability of CD34 and CD105 MVD is consistent with previous studies. Mean microvessel density has been correlated with risk of metastasis, prediction of efficacy of anticancer therapy, and prognosis in a variety of tumour types (Des Guetz et al, 2006; Gadducci et al, 2006; Zhao et al, 2006; Barresi et al, 2007; Calvin et al, 2007; Gulubova and Vlaykova, 2007; Kavantzas et al, 2007; Trivella et al, 2007). The PCI results agree with Eberhard's data (Eberhard et al, 2000). We have found no evidence that mature vasculature with higher PCI responds poorly to CA4P, or that immature $\mathrm{CD} 105^{+}$vasculature responds better. Tumours with higher CD34 MVD may also have higher $\mathrm{CD} 105^{+}$MVD, however it does not necessarily follow that active angiogenesis takes place.

There are a number of aspects of this study that undermine the power of our conclusions. We obtained only small numbers of samples with a heterogeneous mix of different tumour types. However, our sample was limited to patients who had received CA4P and undergone DCE-MRI. Within the ANOVA categorical analysis especially, this greatly reduced the statistical power. Our paraffin blocks, up to 21-year old, were taken from the primary surgical procedure, whereas patients received CA4P during phase I trials many years later after metastatic relapse. It is still unclear whether antigenicity within paraffin blocks reduces over time (Fergenbaum et al, 2004). There are also suggestions that the angiogenic phenotype might continuously evolve from primary tumour through to metastasis (Sullivan and Graham, 2007).

There were widespread falls in MRI kinetic variables following CA4P, however for most patients these did not achieve statistical significance. For some this was because the CA4P dose received was below the threshold level for DCE-MRI detectable drug activity of $50 \mathrm{mg} \mathrm{m}^{-2}$ (Galbraith et al, 2003) - for others the CA4P simply did not have the expected tumour blood flow effect. The reason for administration of the lower CA4P doses in a few patients was the dose escalation protocol for the phase I trial that revealed this phenomenon. $95 \%$ CI for $K^{\text {trans }}$ change was -62.5 to $+166.5 \%$, IAUGC $_{60} \pm 80 \%$. Conversely, taking the two separate trials individually, in $\mathrm{PH} 1 / 066$ the lower $95 \%$ confidence limit for $K^{\text {trans }}$ was $-44 \%$ and in $\mathrm{PH} 1 / 092$ it was $-76.5 \%$. This wide DCE-MRI parameter variability is in line with previously published data (Padhani et al, 2002; Taylor et al, 2004, 2006). Combining DCEMRI data can adversely affect statistical confidence intervals due to the slight differences in sequences and calibration methods used (Taylor et al, 2006). There was wide intrapatient variability, patient motion, and an estimated arterial input function. Modified Fritz-Hansen arterial input coefficients, which are currently used, demonstrate better reproducibility (Fritz-Hansen et al, 1996; Taylor et al, 2007). Averaging the kinetic parameters over a whole lesion also dilutes the effect of CA4P central vascular shutdown because of relative sparing at the tumour periphery.

There was no obvious visual relationship between CA4P dose and fall in MRI parameters. Most patients treated with 
Table 5a Correlation coefficients $\left(r^{2}\right)$ and statistical significance between continuous variables and MRI parameters $(n=21)$

\begin{tabular}{|c|c|c|c|c|c|c|}
\hline \multirow[b]{2}{*}{ MRI parameter } & \multicolumn{6}{|c|}{ Continuous immunohistochemical variable } \\
\hline & CD34 MVD & $\alpha$ SMA PCI & CDI05 MVD & CD6I MVD & Ki-67 (\%) & Glut-I (\%) \\
\hline $\begin{array}{l}K^{\text {trans }} \text { per min } \\
\text { IAUGC }_{60} \mathrm{mM} \text { Gd per s }\end{array}$ & $\begin{array}{l}r^{2}<-0.001 \\
P=0.98 \\
r^{2}<-0.001 \\
P=0.899\end{array}$ & $\begin{array}{l}r^{2}=-0.079 \\
P=0.23 \\
r^{2}=-0.095 \\
P=0.185\end{array}$ & $\begin{array}{l}r^{2}<-0.001 \\
P=0.957 \\
r^{2}=-0.002 \\
P=0.852\end{array}$ & $\begin{array}{l}r^{2}=-0.011 \\
P=0.539 \\
r^{2}<-0.001 \\
P=0.925\end{array}$ & $\begin{array}{l}r^{2}=-0.077 \\
P=0.233 \\
r^{2}=-0.011 \\
P=0.478\end{array}$ & $\begin{array}{l}r^{2}=0.018 \\
P=0.488 \\
r^{2}=0.036 \\
P=0.422\end{array}$ \\
\hline
\end{tabular}

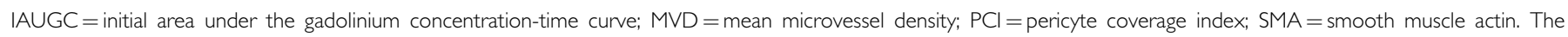
majority of calculations yield a negative regression line ie fall in MRI parameter following CA4P is greater if higher MVD.

Table 5b ANOVA test for relationships between categorical variables and MRI parameters

\begin{tabular}{lcccc}
\hline & \multicolumn{4}{c}{ Categorical variable } \\
\cline { 2 - 5 } MRI parameter & Ang-I & Ang-2 & PDGF & VEGF \\
\hline$K^{\text {trans }}$ per min & $\mathrm{F}=0.965$ & $\mathrm{~F}=3.812$ & $\mathrm{~F}=0.197$ & $\mathrm{~F}=1.654$ \\
& d.f. $(3,15)$ & d.f. $(2,16)$ & d.f. $(2,16)$ & d.f. $(3,16)$ \\
IAUGC 60 mM Gd per $\mathrm{s}$ & $P=0.435$ & $P=0.044$ & $P=0.823$ & $P=0.217$ \\
& $\mathrm{~F}=1.284$ & $\mathrm{~F}=1.728$ & $\mathrm{~F}=0.468$ & $\mathrm{~F}=2.064$ \\
& d.f. $(3,15)$ & d.f. $(2,16)$ & d.f. $(2,16)$ & d.f. $(3,16)$ \\
& $P=0.316$ & $P=0.209$ & $P=0.635$ & $P=0.145$ \\
\hline
\end{tabular}

F-value, degrees of freedom, and $P$-value are shown.

$>50 \mathrm{mg} \mathrm{m}^{-2}$ show reductions in MRI variables, and examining those patients' results in Table 4 there is clearly no correlation, confirmed statistically. Several patients received lower, possibly inactive doses of CA4P. A threshold relationship for DCE-MRI detectable CA4P activity, with patients receiving $>50 \mathrm{mg} \mathrm{m}^{-2}$ exhibiting greater parameter falls has previously been demonstrated (Galbraith et al, 2003; Rustin et al, 2003).

Microvessel density does not reflect the functional properties of vessels, including permeability, which contribute to DCE-MRI variables. Studies reporting correlation between MRI variables and MVD have therefore found only moderate associations ( $\mathrm{Su}$ et al, 2003; Tuncbilek et al, 2004). Several studies (Buckley et al, 1997; Stomper et al, 1997; Su et al, 2003) show conflicting data relating immunohistochemical expression with DCE-MRI data. The different analysis methods used may have affected the results. Hawighorst et al (1998) showed that MRI parameters were better indicators of patient survival than MVD or VEGF.

\section{REFERENCES}

Ahmad SA, Liu W, Jung YD, Fan F, Reinmuth N, Bucana CD, Ellis LM (2001) Differential expression of angiopoietin-1 and angiopoietin-2 in colon carcinoma. A possible mechanism for the initiation of angiogenesis. Cancer 92: $1138-1143$

Bach F, Uddin FJ, Burke D (2007) Angiopoietins in malignancy. Eur J Surg Oncol 33: 7-15

Barnhill RL, Xiao M, Graves D, Antoniades HN (1996) Expression of platelet-derived growth factor (PDGF)-A, PDGF-B and the PDGF-alpha receptor, but not the PDGF-beta receptor, in human malignant melanoma in vivo. Br J Dermatol 135: 898-904

Barresi V, Cerasoli S, Vitarelli E, Tuccari G (2007) Density of microvessels positive for CD105 (endoglin) is related to prognosis in meningiomas. Acta Neuropathol (Berl) 114: 147-156

Bland J, Altman D (1996) Measurement error proportional to the mean. BMJ 313: 744

Buckley DL, Drew PJ, Mussurakis S, Monson JR, Horsman A (1997) Microvessel density of invasive breast cancer assessed by dynamic Gd-DTPA enhanced MRI. J Magn Reson Imaging 7: 461-464
The significant correlation between ang-2 and $K^{\text {trans }}$ is probably a statistical quirk due to the number of variables investigated. However, it might be explained as: angiopoietins are involved in the angiogenic switch (Ahmad et al, 2001; Tanaka et al, 2003). Ang-1 stabilises vessels by maintaining pericyte coverage; ang-2 promotes pericyte removal, which in the presence of VEGF facilitates the angiogenic response and in the absence of VEGF induces vessel regression (Moon et al, 2006; Bach et al, 2007; Shim et al, 2007; Winter et al, 2007). Depending on the tumour model, stabilisation of blood vessels by ang-1 may either promote tumour angiogenesis or reduce tumour growth (Metheny-Barlow and $\mathrm{Li}$, 2003). Wang (Wang et al, 2007) has shown ang-2 correlates with active angiogenesis in human colorectal carcinomas, and that ang2 also correlates with VEGF. Thus, unstable immature ang-2 expressing vasculature undergoing neoangiogenesis is probably more susceptible to the effects of VDAs and thus detectable by DCE-MRI.

In conclusion, there was wide intrapatient variability in angiogenic profile expression and DCE-MRI kinetic variable changes following CA4P. There was no obvious correlation between falls in MRI variables and vascular markers, however sample numbers were small. Immunohistochemical analysis of patients' tumours is unlikely to be useful in predicting response to VDA therapy. This was an exploratory study, which we hoped would suggest some leads for further analysis. Although one could postulate that this study should be expanded to look at larger patient numbers and use fresh tumour samples from a homogeneous group, such a study is unlikely ever to be performed.

\section{Conflict of interest}

None.

Calvin DP, Hammond ME, Pajak TF, Trotti AM, Meredith RF, Rotman M, Jones CU, Byhardt RW, Demas WF, Ang KK, Fu KK (2007) Microvessel density $>$ or $=60$ does not predict for outcome after radiation treatment for locally advanced head and neck squamous cell carcinoma: results of a correlative study from the Radiation Therapy Oncology Group (RTOG) 90-03 Trial. Am J Clin Oncol 30: 406-419

d'Arcy JA, Collins DJ, Padhani AR, Walker-Samuel S, Suckling J, Leach MO (2006) Informatics in radiology. Magnetic resonance imaging workbench: analysis and visualisation of dynamic contrast enhanced MR imaging data. Radiographics 26: 621-632

Des Guetz G, Uzzan B, Nicolas P, Cucherat M, Morere JF, Benamouzig R, Breau JL, Perret GY (2006) Microvessel density and VEGF expression are prognostic factors in colorectal cancer. Meta-analysis of the literature. Br J Cancer 94: 1823 - 1832

Eberhard A, Kahlert S, Goede V, Hemmerlein B, Plate KH, Augustin HG (2000) Heterogeneity of angiogenesis and blood vessel maturation in human tumors: implications for antiangiogenic tumor therapies. Cancer Res 60: $1388-1393$ 
Erdem O, Erdem M, Erdem A, Memis L, Akyol G (2007) Expression of vascular endothelial growth factor and assessment of microvascular density with CD 34 and endoglin in proliferative endometrium, endometrial hyperplasia, and endometrial carcinoma. Int J Gynecol Cancer 17: $1327-1332$

Evelhoch JL (1999) Key factors in the acquisition of contrast kinetic data for oncology. J Magn Reson Imaging 10: 254-259

Evelhoch JL, LoRusso PM, He Z, DelProposto Z, Polin L, Corbett TH, Langmuir P, Wheeler C, Stone A, Leadbetter J, Ryan AJ, Blakey DC, Waterton JC (2004) Magnetic resonance imaging measurements of the response of murine and human tumors to the vascular-targeting agent ZD6126. Clin Cancer Res 10: $3650-3657$

Fergenbaum J, Garcia-Closas M, Hewitt S, Lissowska J, Sakoda L, Sherman $M$ (2004) Loss of antigenicity in stored sections of breast cancer tissue microarrays. Cancer Epidemiol Biomarkers Prev 13: 667-672

Fritz-Hansen T, Rostrup E, Larsson HB, Sondergaard L, Ring P, Henriksen O (1996) Measurement of the arterial concentration of Gd-DTPA using MRI: a step toward quantitative perfusion imaging. Magn Reson Med 36: $225-231$

Gadducci A, Ferrero A, Cosio S, Zola P, Viacava P, Dompe D, Fanelli G, Ravarino N, Motta M, Cristofani R, Genazzani AR (2006) Intratumoral microvessel density in advanced epithelial ovarian cancer and its use as a prognostic variable. Anticancer Res 26: 3925-3932

Galbraith SM, Maxwell RJ, Lodge MA, Tozer GM, Wilson J, Taylor NJ, Stirling JJ, Sena L, Padhani AR, Rustin GJ (2003) Combretastatin A4 phosphate has tumor antivascular activity in rat and man as demonstrated by dynamic magnetic resonance imaging. J Clin Oncol 21: $2831-2842$

Gulubova M, Vlaykova T (2007) Prognostic significance of mast cell number and microvascular density for the survival of patients with primary colorectal cancer. J Gastroenterol Hepatol, doi:10.1111/j.14401746.2007.05009.X

Hawighorst H, Weikel W, Knapstein PG, Knopp MV, Zuna I, Schonberg SO, Vaupel P, van Kaick G (1998) Angiogenic activity of cervical carcinoma: assessment by functional magnetic resonance imaging-based parameters and a histomorphological approach in correlation with disease outcome. Clin Cancer Res 4: 2305-2312

Lind AJ, Wikstrom P, Granfors T, Egevad L, Stattin P, Bergh A (2005) Angiopoietin 2 expression is related to histological grade, vascular density, metastases, and outcome in prostate cancer. Prostate 62: 394-399

Kavantzas N, Paraskevakou H, Tseleni-Balafouta S, Aroni K, Athanassiades P, Agrogiannis G, Patsouris E (2007) Association between microvessel density and histologic grade in renal cell carcinomas. Pathol Oncol Res 13: $145-148$

Metheny-Barlow LJ, Li LY (2003) The enigmatic role of angiopoietin-1 in tumor angiogenesis. Cell Res 13: 309-317

Moon WS, Park HS, Yu KH, Jang KY, Kang MJ, Park H, Tarnawski AS (2006) Expression of angiopoietin 1, 2 and their common receptor Tie2 in human gastric carcinoma: implication for angiogenesis. J Korean Med Sci 21: $272-278$

Padhani AR, Hayes C, Landau S, Leach MO (2002) Reproducibility of quantitative dynamic MRI of normal human tissues. NMR Biomed 15: $143-154$

Parker G, Suckling J, Tanner S, Padhani A, Revell P, Husband J, Leach M (1997) Probing tumor microvascularity by measurement, analysis and display of contrast agent uptake kinetics. J Magn Reson Imaging 7: 564-574

Rustin GJ, Galbraith SM, Anderson H, Stratford M, Folkes LK, Sena L, Gumbrell L, Price PM (2003) Phase I clinical trial of weekly combretastatin A4 phosphate: clinical and pharmacokinetic results. J Clin Oncol 21: 2815-2822
Shim WS, Ho IA, Wong PE (2007) Angiopoietin: a TIE(d) balance in tumor angiogenesis. Mol Cancer Res 5: 655-665

Stomper PC, Winston JS, Herman S, Klippenstein DL, Arredondo MA, Blumenson LE (1997) Angiogenesis and dynamic MR imaging gadolinium enhancement of malignant and benign breast lesions. Breast Cancer Res Treat 45: 39-46

Su MY, Cheung YC, Fruehauf JP, Yu H, Nalcioglu O, Mechetner E, Kyshtoobayeva A, Chen SC, Hsueh S, McLaren CE, Wan YL (2003) Correlation of dynamic contrast enhancement MRI parameters with microvessel density and VEGF for assessment of angiogenesis in breast cancer. J Magn Reson Imaging 18: 467-477

Sullivan R, Graham CH (2007) Hypoxia-driven selection of the metastatic phenotype. Cancer Metastasis Rev 26: 319-331

Tanaka S, Sugimachi K, Yamashita Y, Shirabe K, Shimada M, Wands JR (2003) Angiogenic switch as a molecular target of malignant tumors. J Gastroenterol 38(Suppl 15): 93-97

Taylor N, Lankester K, Ah-See M-L, Stirling J, Rustin G, Makris A, D’Arcy J, Walker-Samuel S, Leach M, Padhani A (2004) Reproducibility of T1 and T2* weighted dynamic contrast-enhanced MRI: a multiparametric comparison of breast and abdominal tumours. Proc ISMRM, abstract 1975

Taylor NJ, d'Arcy JA, Walker-Samuel S, Lankester KJ, Collins DJ, Knowles B, White DL, Miaux Y, Suhy J, Guermazi A, Stirling JJ, Wallace T, Koh D-M, Tang A, Lee C, Rustin GJS, Leach MO, Padhani AR (2006) Single and multi-centre DCE-MRI reproducibility in Phase I clinical trials. In: Proc ISMRM pp. abstract 766: 14th annual meeting

Taylor NJ, Tunariu N, Ah-See M-L, Stirling JJ, Beresford MJ, Makris A, d'Arcy JA, Collins DJ, Padhani AR (2007) Effects of arterial input functions on dynamic MRI kinetic parameter estimates: an analysis of parameter variability and model fitting in breast cancer patients. In: Proc ISMRM pp. abstract 1975: 15th annual meeting

Tofts PS (1997) Modeling tracer kinetics in dynamic Gd-DTPA MR imaging. J Magn Reson Imaging 7: 91-101

Tofts PS, Brix G, Buckley DL, Evelhoch JL, Henderson E, Knopp MV, Larsson HB, Lee TY, Mayr NA, Parker GJ, Port RE, Taylor J, Weisskoff RM (1999) Estimating kinetic parameters from dynamic contrastenhanced $\mathrm{T}(1)$-weighted MRI of a diffusable tracer: standardized quantities and symbols. J Magn Reson Imaging 10: 223-232

Tofts PS, Kermode AG (1991) Measurement of the blood-brain barrier permeability and leakage space using dynamic MR imaging. 1. Fundamental concepts. Magn Reson Med 17: 357-367

Tozer GM, Kanthou C, Baguley BC (2005) Disrupting tumour blood vessels. Nat Rev Cancer 5: 423-435

Trivella M, Pezzella F, Pastorino U, Harris AL, Altman DG (2007) Microvessel density as a prognostic factor in non-small-cell lung carcinoma: a meta-analysis of individual patient data. Lancet Oncol 8: $488-499$

Tuncbilek N, Karakas HM, Altaner S (2004) Dynamic MRI in indirect estimation of microvessel density, histologic grade, and prognosis in colorectal adenocarcinomas. Abdom Imaging 29: 166-172

Wang HL, Deng CS, Lin J, Pan DY, Zou ZY, Zhou XY (2007) Expression of angiopoietin-2 is correlated with vascularization and tumor size in human colorectal adenocarcinoma. Tohoku J Exp Med 213: $33-40$

Winter SF, Acevedo VD, Gangula RD, Freeman KW, Spencer DM, Greenberg NM (2007) Conditional activation of FGFR1 in the prostate epithelium induces angiogenesis with concomitant differential regulation of Ang-1 and Ang-2. Oncogene 26: 4897-4907

Zhao HC, Qin R, Chen XX, Sheng X, Wu JF, Wang DB, Chen GH (2006) Microvessel density is a prognostic marker of human gastric cancer. World J Gastroenterol 12: 7598-7603 